\title{
APPLICATION OF REMOTE SENSING IN GEOLOGICAL MAPPING, CASE STUDY AI MAGHRABAH AREA - HAJJAH REGION, YEMEN
}

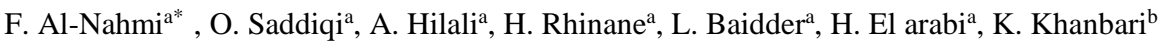

${ }^{a}$ Laboratory Geosciences, Department of Geology, Faculty of Sciences, Hassan II University Casablanca, Morocco (geofuad, lbaidder, h.rhinane)@gmail.com, (o.saddiqi, h.elarabi)@ fsac.ac.ma, hilaliat@yahoo.fr

bYemen Remote Sensing and GIS Centre, Sana'a University, Yemen - kkhanbari@ hotmail.com

\begin{abstract}
KEY WORDS: Satellite imagery, Geological map, Sentinel-2, OIF, ICA, MNF, Yemen
\end{abstract}
\begin{abstract}
:
Remote sensing technology plays an important role today in the geological survey, mapping, analysis and interpretation, which provides a unique opportunity to investigate the geological characteristics of the remote areas of the earth's surface without the need to gain access to an area on the ground. The aim of this study is achievement a geological map of the study area. The data utilizes is Sentinel-2 imagery, the processes used in this study, the OIF Optimum Index Factor is a statistic value that can be used to select the optimum combination of three bands in a satellite image. It's based on the total variance within bands and correlation coefficient between bands, ICA Independent component analysis $(3,4,6)$ is a statistical and computational technique for revealing hidden factors that underlie sets of random variables, measurements, or signals, MNF Minimum Noise Fraction $(1,2,3)$ is used to determine the inherent dimensionality of image data to segregate noise in the data and to reduce the computational requirements for subsequent processing, Optimum Index Factor is a good method for choosing the best band for lithological mapping. ICA, MNF, also a practical way to extract the structural geology maps. The results in this paper indicate that, the studied area can be divided into four main geological units: Basement rocks (Meta volcanic, Meta sediments), Sedimentary rocks, Intrusive rocks, volcanic rocks. The method used in this study offers great potential for lithological mapping, by using Sentinel-2 imagery, the results were compared with existing geologic maps and were superior and could be used to update the existing maps.
\end{abstract}

\section{INTRODUCTION}

Application of remote sensing technology have opened a new era in the field of applied geology, its helps us to learn new methods to identify the types of rocks and tectonic events, which have affected the composition of these rocks. The Precambrian basement complex of Yemen represents the southern extension of the Arabian Nubian Shield. It occupies about $105,000 \mathrm{~km}^{2}$, and is exposed as a vast triangular area in the western part of the country, and as smaller isolated masses to the west and north along the Red Sea coast. This complex occurs between the southern tip of the Arabian-Nubian Shield and the Mozambique Belt, (Abdel Wahed et al. 2006). The target area is covering by the rocks ranging in age from preCambrian rocks to Tertiary rocks, which consists of formations pre-Cambrian rocks are generally Meta - sedimentary and metavolcanic rocks, granites intrusive, (GSMB, 2006). The application of remote sensing for the mapping of regional structure has a long tradition worldwide (Ilhan, $\mathrm{K}$ and Vytautas, k, 1978, Tarik Bashir Benomar and Blan Fuling, 2005, Sandra Jakob et al, 2015). In investigating this area an enhanced Sentinel-2 image was processed and analysed to identify surface structural features, natural colour band $(4,3,2)$, colour infrared band $(8,4,3)$ good for vegetation identification, shortwave infrared band $(12,11,8 \mathrm{a})$ good for mapping fire scars of burnt area (Geosage, Sentinel-2 Image Sources, n.d, para. 3). The resulting product of Sentinel-2 were compared to the local geologic map of the imaged hydrothermal area and it is shown that they support the existing conceptual geologic model of the epithermal deposit, (F.D. van der Meer et al. 2014). The usage of multispectral imagers, such as the Operational Land Imager aboard Landsat- 8 and Sentinel-2 in combination with hyperspectral spaceborne instruments such as Hyperion and EnMAP, will increase in geological mapping and exploration campaigns to reduce airborne related costs to a minimum possible extent, (Christian Mielke et al. 2014). Contribution of Sentinel-2 data for applications in vegetation monitoring, (Pia Addabbo et al. 2016). Mapping Glacier Extents and Surface Facies, and Comparison to Landsat 8, (Frank Paul et al. 2016). In this study, Optimum Index Factor (OIF) methods were used to determine the best Red-Green-Blue (RGB) band combination of satellite images, (Qaid and Basavarajappa, 2008., Pournamdari et al.2014). Independent component analysis (ICA) is a technique for separating a mixture of signals into its components, (Comon, 1994, Stone, 2004), have been proposed to provide an objective approach to accomplish this goal. The minimum noise fraction (MNF) transformation is used to determine the inherent dimensionality of image data, to segregate noise in the data, and to reduce the computational requirements for subsequent processing, (Qari et al.2008). Optimum index factor (OIF), independent component analysis (ICA), and minimum noise fraction (MNF) were implemented to enhance the visual interpretation for revealing geological mapping of the area, thus increasing the possibilities for extracting useful geological information and interpretation the geological events.

\section{GEOLOGICAL SETTING}

Geology of Hajjah region is very complex, because they are exposed to several geological events, the area study is a part of the Arabian-Nubian Shield, which is part of the East African Orogen formed by plate tectonic accretionary events during the closure of Mozambique Ocean and subsequent collision of east and west Gondwana at about $540 \mathrm{Ma}$, (Heikal et al. 2013). The area covering by The Precambrian rocks in Yemen outcrop in the western part of the country as this region experienced basement uplift related to the Red Sea and Gulf of Aden rift events, (As-Saruri et al. 2010). The rocks units in Hajjah region are various, it is exposed at the surface that generally consists of

* Corresponding author 
Meta-volcanic, Meta-gabbro, Syn-tectonic granitoid, Latetectonic granitoid, and Jurassic sedimentary rocks (Heikal, 1989), figure 1. These rocks are intruded by gabbro, Syntectonic, post-tectonic granite and granodiorites. (Qaid and Basavarajappa, 2008), The area exposer for several deformations during Post-Thrust, characterized by compression only giving rise to major and minor folds which are trending NNW and NNE, (Hajjah area, Asir Terrane). (Heikal el al 2013). The terranes in Yemen may be correlated with comparable terranes on the eastern margin of the Arabian Shield and in northern Somalia. Thus, Yemen provides a link between the arc collage of the Arabian Shield and the gneissic Mozambique belt of East Africa, ( Windley et al. 1996).
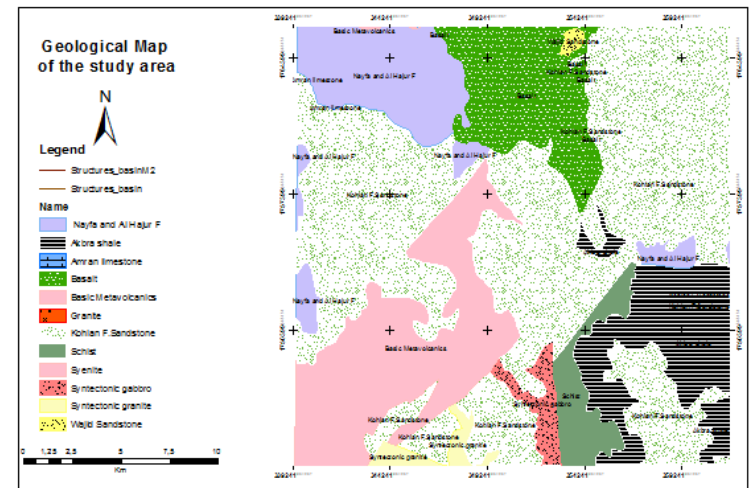

Figure 1. Geological map of the area scale 1:250.000, YGSMB

\section{STUDY AREA LOCATION}

The study area is located between longitudes E $43^{\circ} 30^{\prime}-43^{\circ} 45^{\prime}$ and latitudes $\mathrm{N} 15^{\circ} 45^{\prime}-16^{\circ} 00^{\prime}$.in the southeast of Hajjah governorate, north west of Yemen, the relief of the area is mountainous with moderate to sleep slopes and sharp ridges. The study area access by car, $150 \mathrm{~km}$ from Sana'a. The sea level about 900-1500, meter figure 2, this area has a good potential of mineral exploration in gold deposits, many companies work there and get good results.

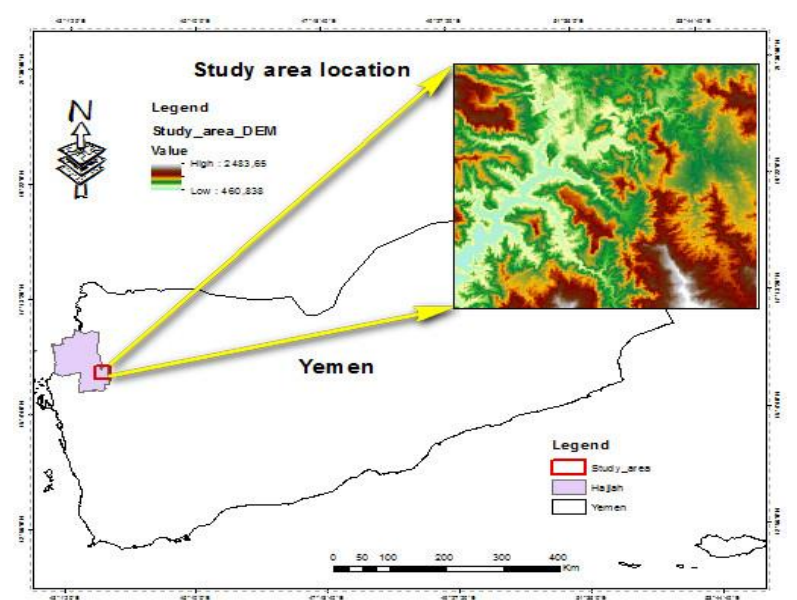

Figure 2. Study area location

\section{METHODOLOGY OF WORK}

When studying the shape of the earth surface, in connection with the rock layers and their deformations by tectonic forces, we often notice a correlation between shapes and structures at the surface and in the subsurface (Short and Blair, 1986). In this study, satellite image Sentinel-2 used and applied the processing such as the Optimum Index Factor (OIF) is a statistic value that can be used to select the optimum combination of three bands in a satellite image with which you want to create a colour composite, independent component analysis (ICA), and minimum noise fraction (MNF), can often improve an image viewer, also a practical way to extract the structural geology maps.

\subsection{Collection and description data}

\subsubsection{Sentinel - 2}

Sentinel-2A satellite sensor was successfully launched on June 23, 2015 at 03.51:58 am CEST from a Vega launcher form the spaceport in Kourou, French Guiana. Sentinel-2A satellite is the first optical Earth observation satellite in the European Copernicus programme and was developed and built under the industrial leadership of Airbus Defence and Space for the European Space Agency (ESA), (Satellite Imaging Corporation, n.d, para. 1)

\begin{tabular}{|l|l|l|}
\hline Sentinel-2 Bands & Central Wavelength $(\mu \mathrm{m})$ & Resolution $(\mathrm{m})$ \\
\hline Band 1 - Coastal aerosol & 0.443 & 60 \\
\hline Band 2-Blue & 0.490 & 10 \\
\hline Band 3 - Green & 0.560 & 10 \\
\hline Band 4 - Red & 0.665 & 10 \\
\hline Band 5 - Vegetation Red Edge & 0.705 & 20 \\
\hline Band 6 - Vegetation Red Edge & 0.740 & 20 \\
\hline Band 7 - Vegetation Red Edge & 0.783 & 20 \\
\hline Band 8 - NR & 0.842 & 10 \\
\hline Band 8A - Narrow NIR & 0.865 & 20 \\
\hline Band 9 - Water vapour & 0.945 & 60 \\
\hline Band 10 - SWRR - Cirnus & 1.375 & 60 \\
\hline Band 11 - SWR & 1.610 & 20 \\
\hline Band 12-SWR & 2.190 & 20 \\
\hline
\end{tabular}

Table 1. Sentinel-2 spectral bands

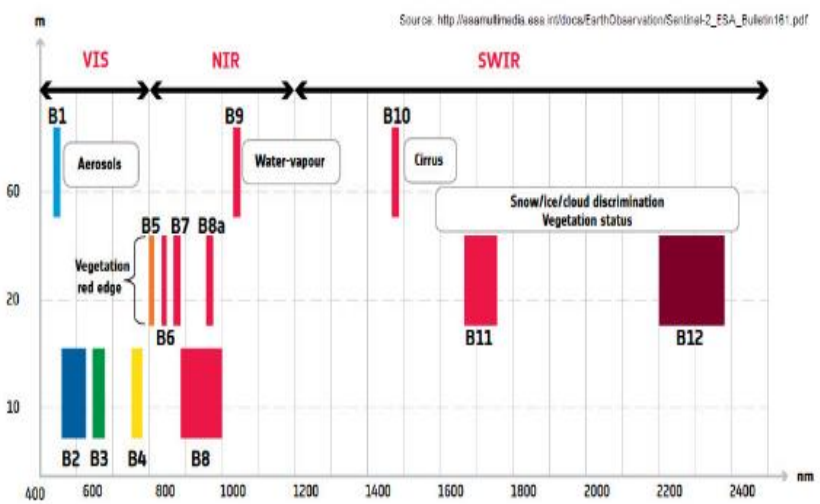

Figure 3. Sentinel-2 spectral bands

Scenes S2A_MSIL1C_20170605T072621_N0205_R049_T38P LC_20170605T074311.zip free downloaded. Multispectral Imager covering 13 spectral bands (443-2190 nm), with a swath width of $290 \mathrm{~km}$ and a spatial resolution of $10 \mathrm{~m}$ (four visible and near-infrared bands), $20 \mathrm{~m}$ (six red edge and shortwave infrared bands) and $60 \mathrm{~m}$ (three atmospheric correction bands). Table 1 and figure 3, Common band combinations for Red/Green/Blue (RGB) imagery composite in Sentinel-2, natural colour $(4,3,2)$, colour infrared, good for vegetation identification $(8,4,3)$, shortwave infrared, SWIR, good for mapping fire scars or burnt areas $(12,11,8 \mathrm{a})$, (Geosage, Sentinel-2 Image Sources, n.d, para. 3) 


\subsection{Remote sensing analysis}

The data used in this study is based mainly on Sentinel-2 imagery. The Remote sensing and GIS software used for processing and mapping the data during the analysis. Arc Map is used mainly for the GIS interpretation (e.g. the statistical analyses of lineaments). Interpretation of images from satellites is based on the spectral reflectance of earth materials on the surface. However, such reflectance depends on the electromagnetic spectrum in which the satellite collects data, (Tsilavo Raharimahefa, Timothy M. Kusky, 2006). Optium index fractures (OIF), independent component analysis (ICA), and minimum noise fraction (MNF), transformation are the main digital image processing techniques performed during this study. The following paragraphs describe each kind of data.

\subsubsection{Optimum Index Factor (OIF)}

Optimum Index Factor (OIF) is a statistic value that can be used to select the optimum combination of three bands in a satellite image with which you want to create a colour composite.

To determine the best band combinations for detection of the different rock units for both ASTER and Landsat TM data, the following formula was used:

$\mathrm{OIF}=\sum \mathrm{si} / \sum \mathrm{I}$ rj I

Where si is the standard deviation for band

$\mathrm{k}, \mathrm{rj}$ is the correlation coefficient between any two of three bands being evaluated. Sometimes the different bands of multispectral images appear similar and are correlated with duplicate information, (Pournamdari et al.2014). In this research the correlation coefficient was employed and calculated for reflective bands of Sentinel-2, table 2. The thirteen reflective Sentinel-2, VNIR + VRE+SWIR bands group after resampling the VRE and SWIR bands $(20 \mathrm{~m})$ to the same resolution as VNIR bands $(10 \mathrm{~m})$. The band group are : (VIS, VIS-VRE, VIS-SWIR, VIS-VRE-SWIR, VNIR, VNIR-VER, VNIR-SWIR, VNIR-VRE-SWIR, VRE, VER-NIR, VRESWIR, VRE-NIR-SWIR, SWIR-NIR), table 3.

\begin{tabular}{lcccccccccc}
\hline & b02 & b03 & b04 & b05 & b06 & b07 & b08 & b08a & b11 & b12 \\
\hline b02 & 1.00 & 0.96 & 0.93 & 0.85 & 0.61 & 0.54 & 0.52 & 0.52 & 0.71 & 0.77 \\
b03 & 0.96 & 1.00 & 0.98 & 0.95 & 0.76 & 0.71 & 0.69 & 0.68 & 0.83 & 0.86 \\
b04 & 0.93 & 0.98 & 1.00 & 0.95 & 0.74 & 0.68 & 0.66 & 0.66 & 0.86 & 0.89 \\
b05 & 0.85 & 0.95 & 0.95 & 1.00 & 0.88 & 0.83 & 0.80 & 0.81 & 0.93 & 0.92 \\
b06 & 0.61 & 0.76 & 0.74 & 0.88 & 1.00 & 0.99 & 0.98 & 0.99 & 0.87 & 0.79 \\
b07 & 0.54 & 0.71 & 0.68 & 0.83 & 0.99 & 1.00 & 0.98 & 0.99 & 0.84 & 0.75 \\
b08 & 0.52 & 0.69 & 0.66 & 0.80 & 0.98 & 0.98 & 1.00 & 0.98 & 0.81 & 0.72 \\
b08a & 0.52 & 0.68 & 0.66 & 0.81 & 0.99 & 0.99 & 0.98 & 1.00 & 0.83 & 0.74 \\
b11 & 0.71 & 0.83 & 0.86 & 0.93 & 0.87 & 0.84 & 0.81 & 0.83 & 1.00 & 0.97 \\
b12 & 0.77 & 0.86 & 0.89 & 0.92 & 0.79 & 0.75 & 0.72 & 0.74 & 0.97 & 1.00 \\
\hline
\end{tabular}

Table 2. Correlation Matrix of the bands

\subsubsection{Minimum Noise Fraction (MNF)}

The minimum noise fraction (MNF) transformation is used to isolate noise from signal in the data set, that mains it used to determine the inherent dimensionality of image data, to segregate noise in the data, and to reduce the computational requirements for subsequent processing, (Boardman and Kruse, 1994) This method is the same of the principal component (PC) analyses that have been used for a long time in multispectral image processing, but involves an extra preceding step. From the above the MNF transform used to: remove residual noise from the spectral data and provide a convenient mechanism for selecting prototype spectra. It was applied to present the utility of multi-spectra optical band images for lithological mapping, which enables the delineation of the rocks units in the study area. MNF was applied on Sentinel-2 images (VNIR-VRESWIR) bands, because they contain suitable information to detect lithology of the rocks. Based on statistical studies, also percentage of data variation, the results show the first band of MNF involved the highest Eigenvalues with lowest noise, and the last band of MNF involved the lowest Eigenvalues with highest noise. Used MNF Band (1,2,3), because it has the high Eigenvalues with lowest noise, it's easy to identification of the rocks unites Figure 4.

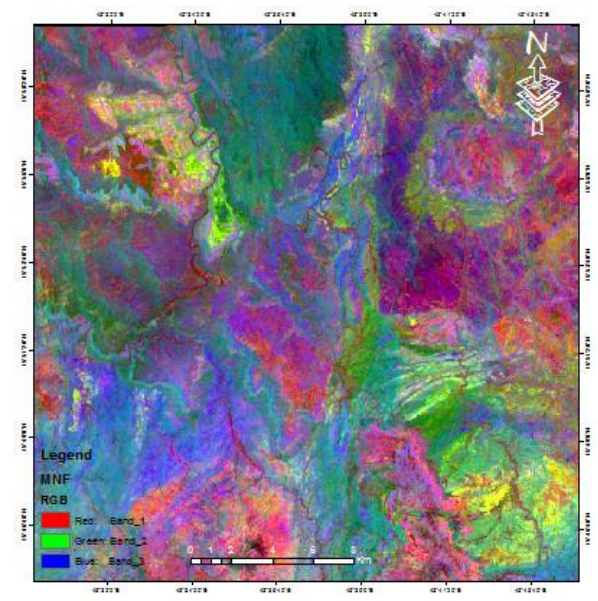

Figure 4. MNF band $(1,2,3)$

\subsubsection{Independent Component Analysis (ICA)}

Independent component analysis (ICA) is a statistical and computational technique for revealing hidden factors that underlie sets of random variables, measurements, or signals. You can see it as an extension to principal component analysis and factor analysis. It's a much more powerful technique, however, capable of finding the underlying factors or sources when these classic methods fail completely, (Aapo Hyvärinen et al.2001). The major advantage of this ICA transforms over PCA and MNF methods is that it is based on the non-Gaussian assumption of the independent sources which is a typical characteristic of hyperspectral datasets, (Veeramallu Satya Sahithi and Iyyanki V Murali Krishna, 2016). It uses higherorder statistics to discover some interesting features in nonGaussian hyperspectral datasets (Yusuf and He, 2011). As PCA and MNF the first band in ICA has the high eigenvalue and the last band has the lowest eigenvalue. ICA band $(3,4,6)$, chose to identification the rocks unite in the study area, figure 5 .

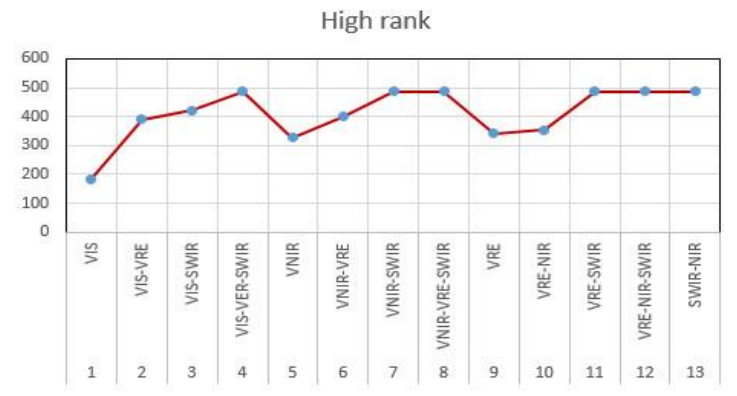

Line graph 1 . The high values of the OIF group 


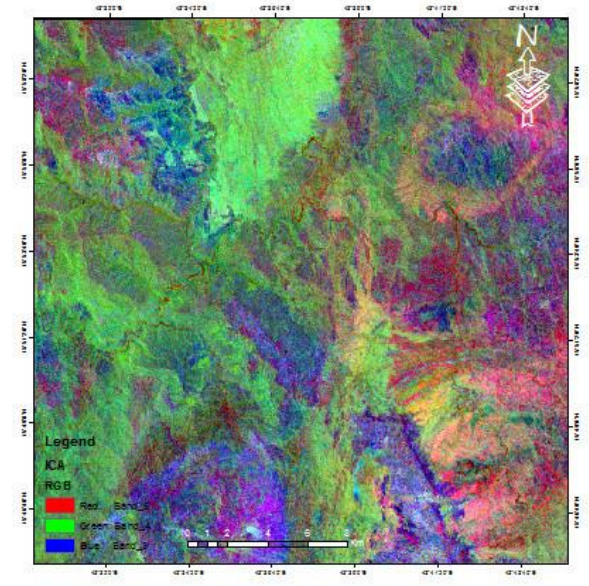

Figure 5. ICA band $(3,4,6)$

\section{RESULTS AND DISCUSSIONS}

In this study, the formations can be easily recognized and their boundaries can be drafted accurately. In fact, the Andesite granite rocks, Meta volcanic rocks, Kohlan sandstone, Amran limestone, and volcanic formations (Paleogene-Neogene Basalt), due to their drainage patterns, can be clearly distinguished from one another. As a result, it is observed that the varies bands depended on the OIF is more convenient for drafting the boundaries of geological formations. However, different formations that affect the vegetation cover appear better on the band $12,8 \mathrm{a}, 4$. Therefore, the band $(12,8 \mathrm{a}, 3)$ or band $(11,8 \mathrm{a}, 2)$, have been used together in complementary fashion for drawing the geological map. The other geological formation boundaries also appear better on band (11, 8a, 4). MNF band $(1,2,3)$, ICA band $(3,4,6)$, enhancement image also helps to easy distinguished between geological formation, in this bands, the light-shadow contrast of landforms is very clear. Therefore, various types of geological.

\subsection{Data analysis}

\subsubsection{Optimum Index Factor (OIF)}

Optimum Index Factor (OIF) is a statistic value that can be used to select the optimum combination of three bands in a satellite image with which you want to create a colour composite, (Qaid and Basavarajappa, 2008, Pournamdari et al.2014). Based on the OIF rate value we have 13 group of composite bands content 64 RGB band combination were obtained from the Sentinel-2 bands, table 3 . in the different electromagnetic spectrum including: visible (VIS), near infrared (NIR), vegetation red edge (VRE), and shortwave infrared (SWIR). The OIF 13 composite bands group involved: (VIS, VIS-VRE, VIS-SWIR, VIS-VRE-SWIR, VNIR, VNIR-VRE, VNIRSWIR, VNIR-VRE-SWIR, VRE, VRE-NIR, VRE-SWIR, VRE-NIR-SWIR, SWIR-NIR). The high rank value of OIF appear in 4 group, VNIR-VRE-SWIR, VRE-NIR-SWIR, VNIR-SWIR, SWIR-NIR, band $(12,11,8)$ with the highest rank value is 488,03 , line graph 1, 2 group, VIS-VRE-SWIR, VRESWIR, band $(12,11,8 \mathrm{a})$, with rank value is 486.09 , group, VISSWIR, band $(12,11,4)$, with rank value is 420.60 , group, VNIRVRE, band $(8 a, 8,4)$, with rank value 400.64 , group, VIS-VRE, bands $(8 \mathrm{a}, 7,4)$, with rank value is 390.18 , group, VRE-NIR, with combination band $(8 \mathrm{a}, 8,5)$ and the rank value is 353.30 , group, VRE, with band combination $(8,7,5)$, and rank value is 340,84 , group, VNIR, with combination band $8,4,2$ and rank value is 327.57 , and group, VIS, with combination band 4,3,2 and rank value is 184.34 , it was the lowest band in the groups, line graph 1 . Some of band combinations comes duplicate in different group, band $(12,11,8 \mathrm{a})$, comes 4 times, band $(12,11,8)$ comes 4 times, band $(12,11,7)$, comes 4 times, band $(12,11,6)$, comes 3 times, band $(11,8 \mathrm{a}, 4)$, comes 2 times, band $(11,8 \mathrm{a}, 2)$, comes 2 times, band $(12,11,4)$, comes 2 times band $(8 \mathrm{a}, 7,4)$, comes 2 times, band $(8 \mathrm{a}, 7,2)$, comes 2 times, band $(8,7,5)$, comes 2 times, band $8 \mathrm{a}, 8,7$ comes 2 times and finally band $(4,3,2)$, comes 2 times, the rest of the band combinations, each one has its own situation.

\section{Analysis the OIF results:}

The result of OIF statistic values indicate, that the composite bands included 13 group, table 2 . And diagram 1. content different band combinations as the following:

VIS: The bands in this group is $2,3,4$, the OIF rank value is 184.34 and the RGB $(4,3,2)$, this band is the low OIF rank value in the groups, so the rocks appear not clear for distinguished, the basalt and Meta-volcanic rocks appear light dark, Tawilah sandstone appear in dimgrey colour, figure 8 . VIS-VRE: The bands in this group is $2,3,4,5,6,7,8 \mathrm{a}$, the OIF rank value is 390.18 and the RGB $(8 \mathrm{a}, 7,4)$, the basalt and Metavolcanic appear in dark blue colour, Tawilah sandstone appear in the light grey color, andesite-granite appear in light yellow colour, figure 9.

VIS-SWIR: The bands in this group is $2,3,4,11,12$, the OIF rank value is 420.60 and the $\operatorname{RGB}(12,11,4)$, the basalt appears in dark black to black, Meta-volcanic appear in brown colour, Tawilah sandstone light yellow colour, Akbar Shale is easy to discriminate because, it appeared as dark blue colour and Kohlan sandstones appeared as yellow colour, figure 10 .

VIS-VRE-SWIR: The bands in this group is $2,3,4,5,6,7,8 \mathrm{a}, 11,12$, the OIF rank value is 486.09 and the RGB $(12,11,8 \mathrm{a})$, this group with others group (VRE-SWIR) have the same rank value, in this group, I choose RGB $(11,8 \mathrm{a}, 4)$, it was very clear and very suitable for lithology map, the basalt appears in blue to light blue, Meta-volcanic appear in rose colour, Tawilah sandstone appear in white to light pink colour, Akbra shale appear in dark blue colour, Amran limestone appear in grey to pink in other side, Andesite granite appear in light green to light grey, Vegetation cover appeared as dark green colour, figure 11. VNIR: The band in this group is $2,3,4,8$, the OIF rank value is 327.57 and the RGB $(8,4,2)$, the basalt and Meta-volcanic appear in black colour, Tawilah sandstone appear in white to light red colour, vegetation appears in red colour, figure 12 .

VNIR-VRE: The band in this group is $2,3,4,5,6,7,8,8 \mathrm{a}$, the OIF rank value is 400.64 and the best RGB is $(8 a, 8,4)$, the Paleogene, Neogene-basalt, Meta-volcanic and Akbra shale appear in the same colour dark blue, cretaceous Tawilah appear in white colour, other rock not clear to descriptions, figure 13. VNIR-SWIR: The bands in this group is $2,3,4,8,11,12$, the OIF rank value is 488.03 , the RGB is $(12,11,8)$, but I used the RGB $(11,8,4)$, the rank is 451.00 , it was suitable for lithology mapping, the Paleogene, Neogene-basalt, appear in the dark blue colour, Meta-volcanic appear in purple colour, Akbra shale appear in colour dark blue, cretaceous Tawilah appear in hot pink to white colour, Jurassic Amran appear in blue violet to violet in other area colour, vegetation appear clear in green colour, figure 14

VNIR-VRE-SWIR: RGB $(12,11,8)$, the rank value 488.03 , it was high value, but I used the RGB $(11,8 \mathrm{a}, 4)$, the rank is 453.69 , it was suitable also for lithology mapping, the Paleogene, Neogene-basalt, appear in the dark blue colour, Meta-volcanic appear in purple colour, Akbra shale appear in colour dark blue, 
cretaceous Tawilah appear in hot pink to white colour, vegetation appears clear in green colour, figure 15.

$V R E$ : The bands in this group is $5,6,7,8 \mathrm{a}$, RGB $(8,7,5)$, the rank value is 340.84 , in this group the basalt and meta-volcanic appear in the black colour, Jurassic Tawilah appear in white to light grey colour, Cretaceous Amran and meta-sediments appear in grey to dark grey colour, the vegetation appear in yellow colour, figure 16 .

VRE-NIR: The bands in this group is 5,6,7,8,8a, RGB $(8 \mathrm{a}, 8,5)$, the rank value is 353.30 , in this group the basalt and metavolcanic appear in the black colour, Jurassic Tawilah appear in white to light grey colour, Cretaceous Amran and metasediments appear in grey to dark grey colour, the vegetation appears in yellow colour, figure 17 .

VRE-SWIR: The bands in this group is 5,6,7,8,8a,11,12, RGB $(12,11,8 \mathrm{a})$, the rank value is 486.09 , in this group the basalt rocks appear in black to dark black, Meta-volcanic appear in brown colour, Jurassic Tawilah in yellow colour, Cretaceous Amran in grey to light yellow, vegetation appears in blue colour, figure 18 .

VRE-NIR-SWIR: The bands in this group is $5,6,7,8,8 \mathrm{a}, 11,12$, $\operatorname{RGB}(12,11,8)$, the rank value is 488.03 , in this group the basalt rocks appear in black to dark black, Meta-volcanic appear in brown colour, Jurassic Tawilah in yellow colour, Cretaceous Amran in grey to light yellow, vegetation appears in light blue colour, figure 19.

SWIR-NIR: RGB $(12,11,8)$, the rank value is 488.03 , this group the same of the group above.

\begin{tabular}{|c|c|c|c|c|c|c|c|}
\hline \multirow[t]{2}{*}{ No } & \multirow[t]{2}{*}{ Group } & \multicolumn{3}{|c|}{$\begin{array}{c}\text { Combinations } \\
\text { Band }\end{array}$} & \multirow[t]{2}{*}{ Bands of the group } & \multirow[t]{2}{*}{$\begin{array}{l}\text { High } \\
\text { Rank }\end{array}$} & \multirow[t]{2}{*}{ Abbreviations of group } \\
\hline & & $\mathrm{R}$ & $\mathrm{G}$ & $\mathrm{B}$ & & & \\
\hline 1 & VIS & 4 & 3 & 2 & $2,3,4$ & 184.34 & \multirow{13}{*}{$\begin{array}{l}\text { VIS : Visible } \\
\text { VNIR: Visible- Infrared } \\
\text { NIR: Near Infrared } \\
\text { VRE: Vegetation Red Edge } \\
\text { SWIR: Short Wave Infrared }\end{array}$} \\
\hline 2 & VIS-VRE & $8 \mathrm{a}$ & 7 & 4 & $2,3,4,5,6,7,8 \mathrm{a}$ & 390.18 & \\
\hline 3 & VIS-SWIR & 12 & 11 & 4 & $2,3,4,11,12$ & 420.60 & \\
\hline 4 & VIS-VER-SWIR & 12 & 11 & $8 \mathrm{a}$ & $2,3,4,5,6,7,8 \mathrm{a}, 11,12$ & 486.09 & \\
\hline 5 & VNIR & 8 & 4 & 2 & $2,3,4,8$ & 327.57 & \\
\hline 6 & VNIR-VRE & $8 \mathrm{a}$ & 8 & 4 & $2,3,4,5,6,7,8,8 \mathrm{a}$ & 400.64 & \\
\hline 7 & VNIR-SWIR & 12 & 11 & 8 & $2,3,4,8,11,12$ & 488.03 & \\
\hline 8 & $\begin{array}{l}\text { VNIR-VRE-SWIR } \\
\end{array}$ & 12 & 11 & 8 & $2,3,4,5,6,7,8,8 \mathrm{a}, 11,12$ & 488.03 & \\
\hline 9 & VRE & 8 & 7 & 5 & $5,6,7,8 \mathrm{a}$ & 340.84 & \\
\hline 10 & VRE-NIR & $8 \mathrm{a}$ & 8 & 5 & $5,6,7,8,8 \mathrm{a}$ & 353.30 & \\
\hline 11 & VRE-SWIR & 12 & 11 & $8 \mathrm{a}$ & $5,6,7,8 \mathrm{a}, 11,12$ & 486.09 & \\
\hline 12 & \begin{tabular}{|l} 
VRE-NIR-SWIR \\
\end{tabular} & 12 & 11 & 8 & $5,6,7,8,8 \mathrm{a}, 11,12$ & 488.03 & \\
\hline 13 & SWIR-NIR & 12 & 11 & 8 & $8,11,12$ & 488.03 & \\
\hline
\end{tabular}

Table 3. Composite band of OIF group

\subsubsection{Enhancement images}

\subsubsection{Minimum Noise Fraction (MNF)}

The minimum (or maximum) noise fraction (MNF) transformation is used to isolate noise from signal in the data set, and to reduce the computational requirements for subsequent processing, (Boardman and Kruse, 1994). MNF was applied on Sentinel-2 images (VNIR-VRE-SWIR) bands, because they contain suitable information to detect lithology of the rocks. Based on statistical studies, also percentage of data variation, the results show the first band of MNF involved the highest Eigenvalues with lowest noise, and the last band involved the lowest Eigenvalues with highest noise. Used MNF Band $(1,2,3)$, because they have the high Eigenvalues with lowest noise. The band combinations $(1,2,3)$ appear the rock units of the basalt in light green colour, Meta-volcanic in blue colour, Andesite granite in multi coloured, Amran limestone appear in light blue in some areas and pink in other areas, Wadi deposits not clear, figure 6 .

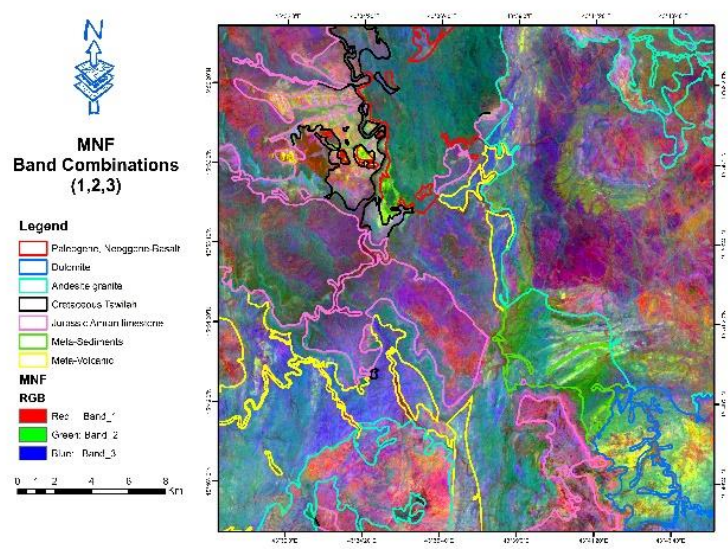

Figure 6. MNF band $(1,2,3)$

\subsubsection{Independent Component Analysis (ICA)}

The independent component analysis (ICA) of a random vector consists of searching for a linear transformation that minimizes the statistical dependence between its components. In order to define suitable search criteria, the expansion of mutual information is utilized as a function of cumulants of increasing orders. The concept of ICA appear as an extension of the principal component analysis (PCA), (Pierre Comon, 1994). It's a much more powerful technique, however, capable of finding the underlying factors or sources when these classic methods fail completely. ICA were applied to present the utility of multispectra optical band images for lithological mapping, which enables the delineation of the main rocks units, that exist in the study area. The first bands involved the highest eigenvalues, and the last bands involved the lowest eigenvalues. The band combinations $(3,4,6)$ was containing suitable information to detect the lithology of rocks. the rock units of the basalt appear in green colour, Meta-volcanic not clear, Andesite granite appear in multi coloured, Amran limestone appear in light green in some areas and blue in other areas, vegetation not clear, figure 7.

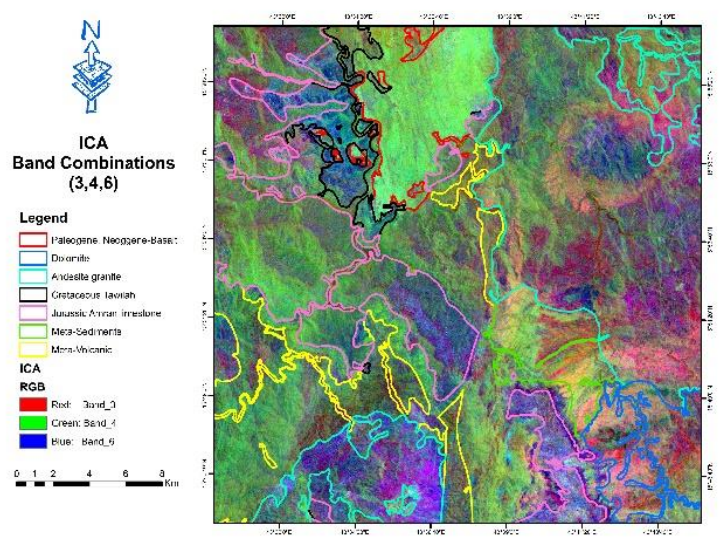

Figure 7. ICA band $(3,4,6)$ 


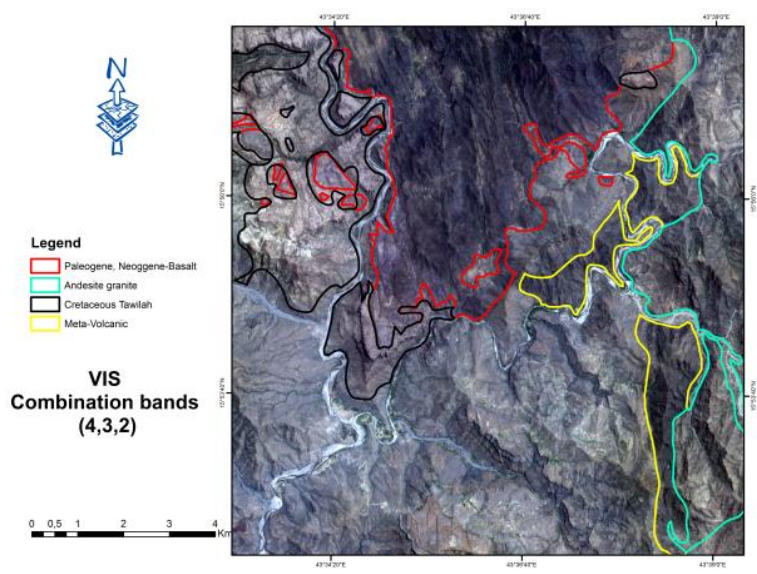

Figure 8 . VIS band $(4,3,2)$

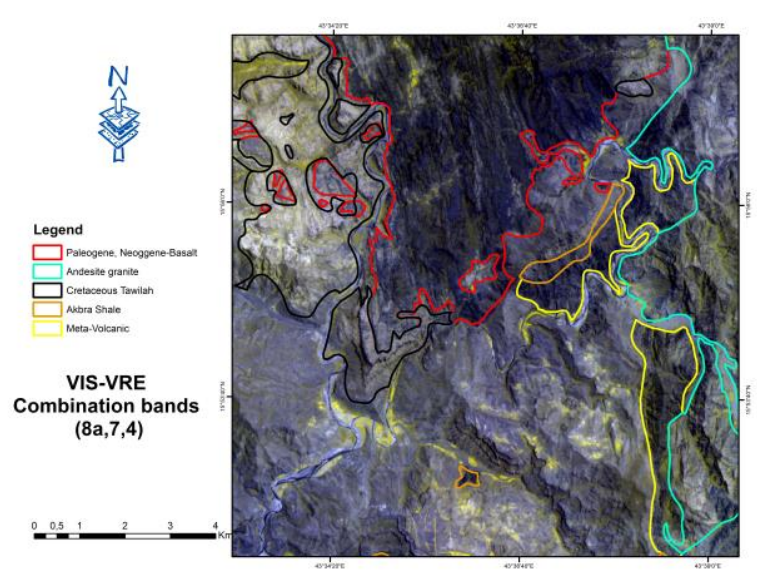

Figure 9. VIS-VRE band $(8 \mathrm{a}, 7,4)$

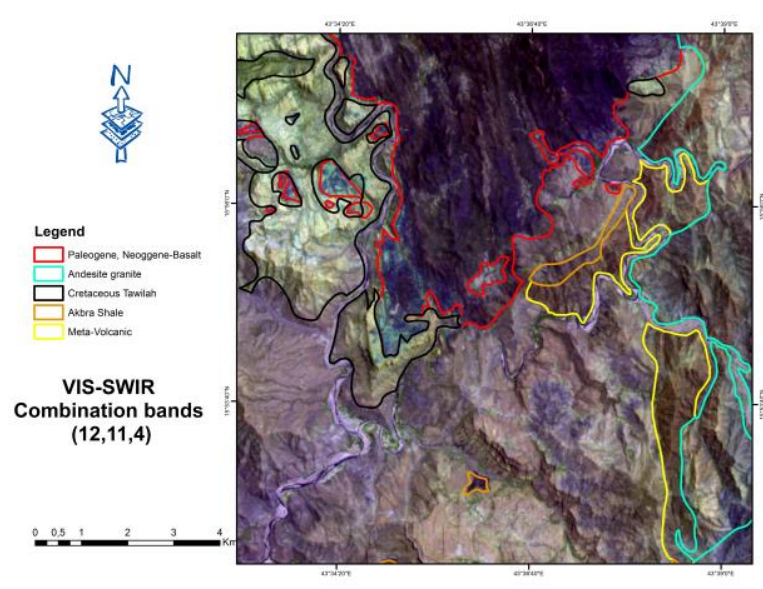

Figure 10. VIS-SWIR band $(12,11,4)$

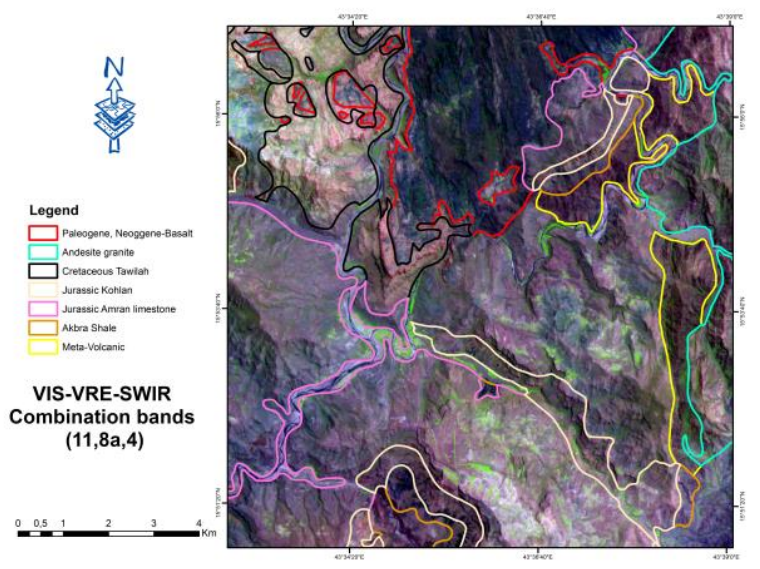

Figure 11. VIS-VRE-SWIR band $(11,8 \mathrm{a}, 4)$

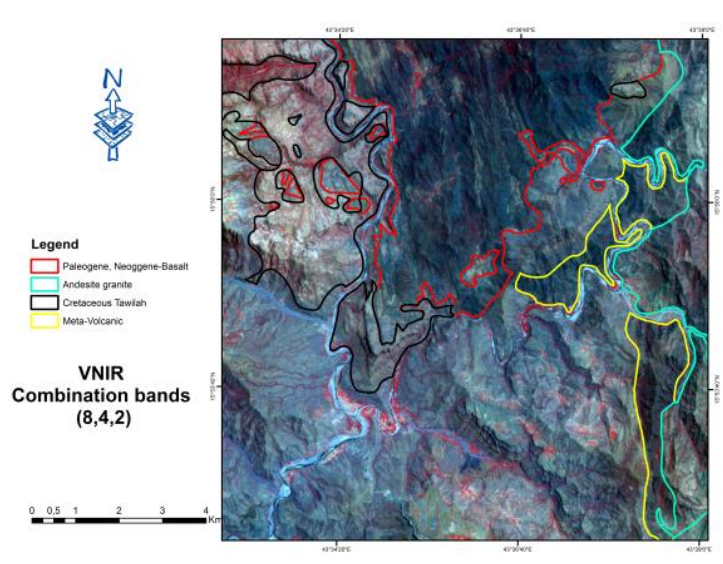

Figure 12. VNIR band $(8,4,2)$

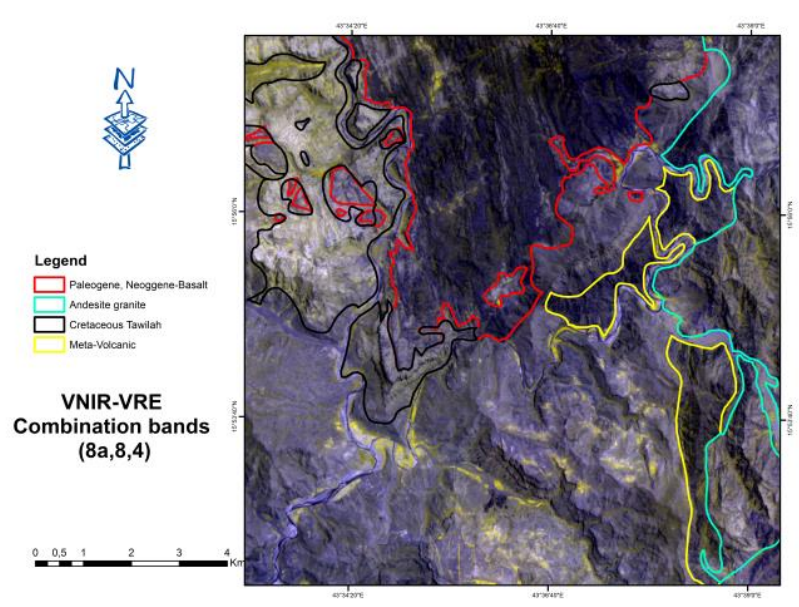

Figure 13. VNIR-VRE band $(8 \mathrm{a}, 8,4)$ 


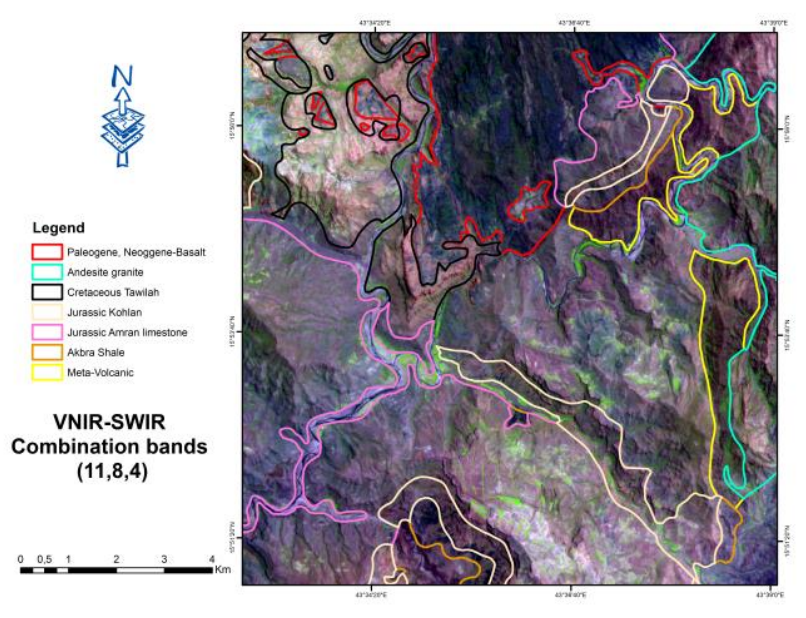

Figure 14. VNIR-SWIR band $(11,8,4)$

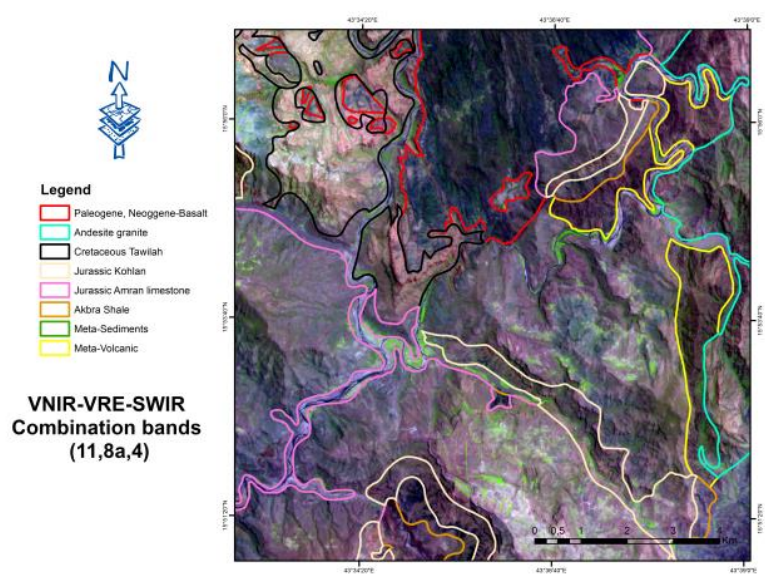

Figure 15. VNIR-VRE-SWIR band $(11,8 \mathrm{a}, 4)$

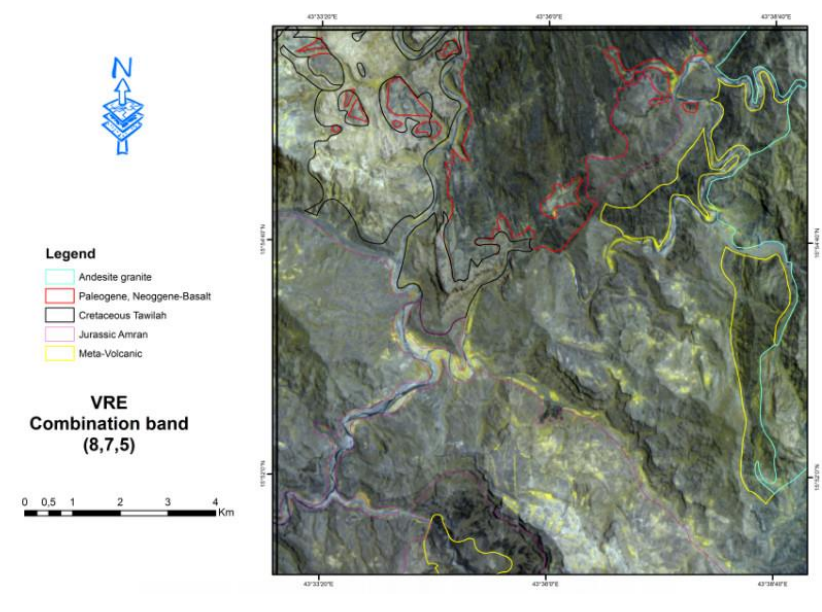

Figure 16. VRE band $(8,7,5)$
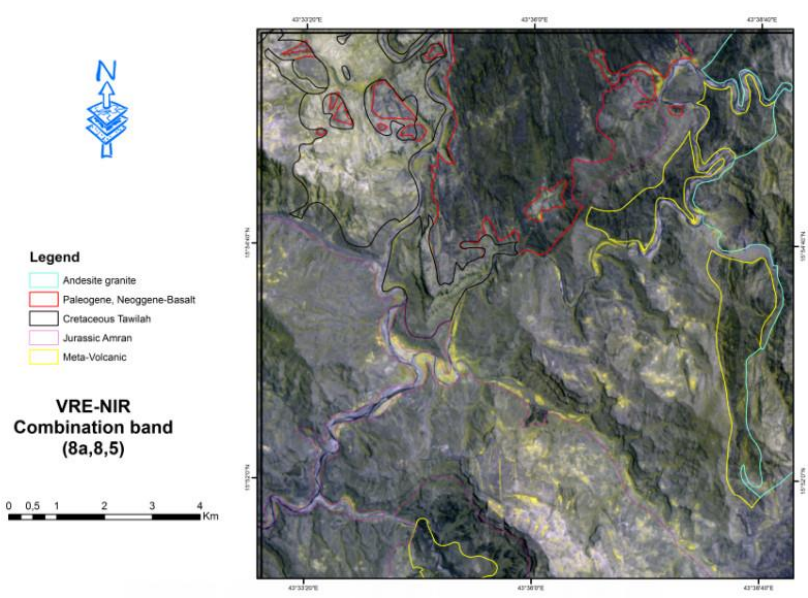

Figure 17. VRE-NIR band $(8 \mathrm{a}, 8,5)$
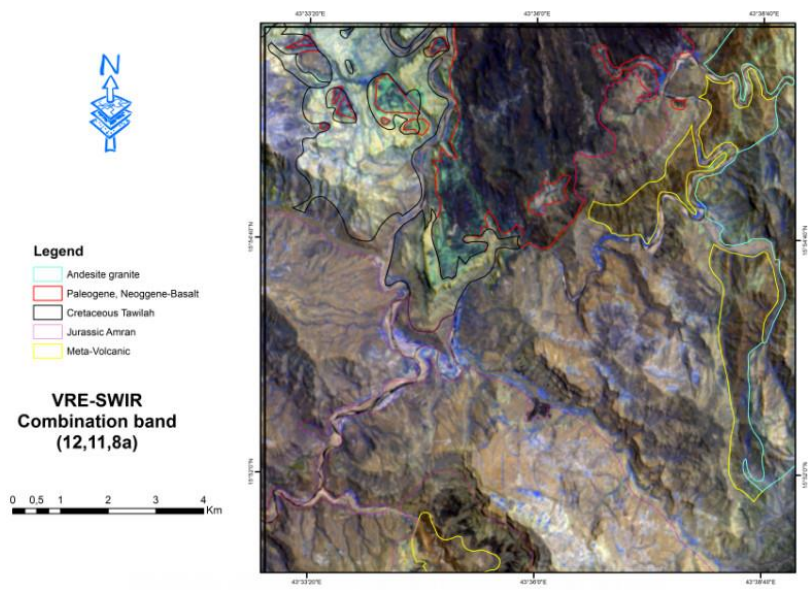

Figure 18. VER-SWIR band (12,11,8a)
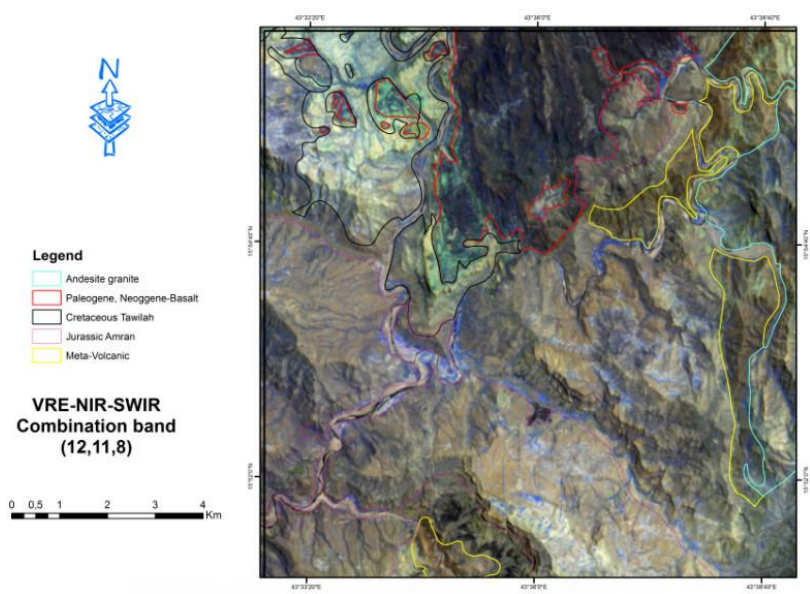

Figure 19. VRE-NIR-SWIR band $(12,11,8)$ 


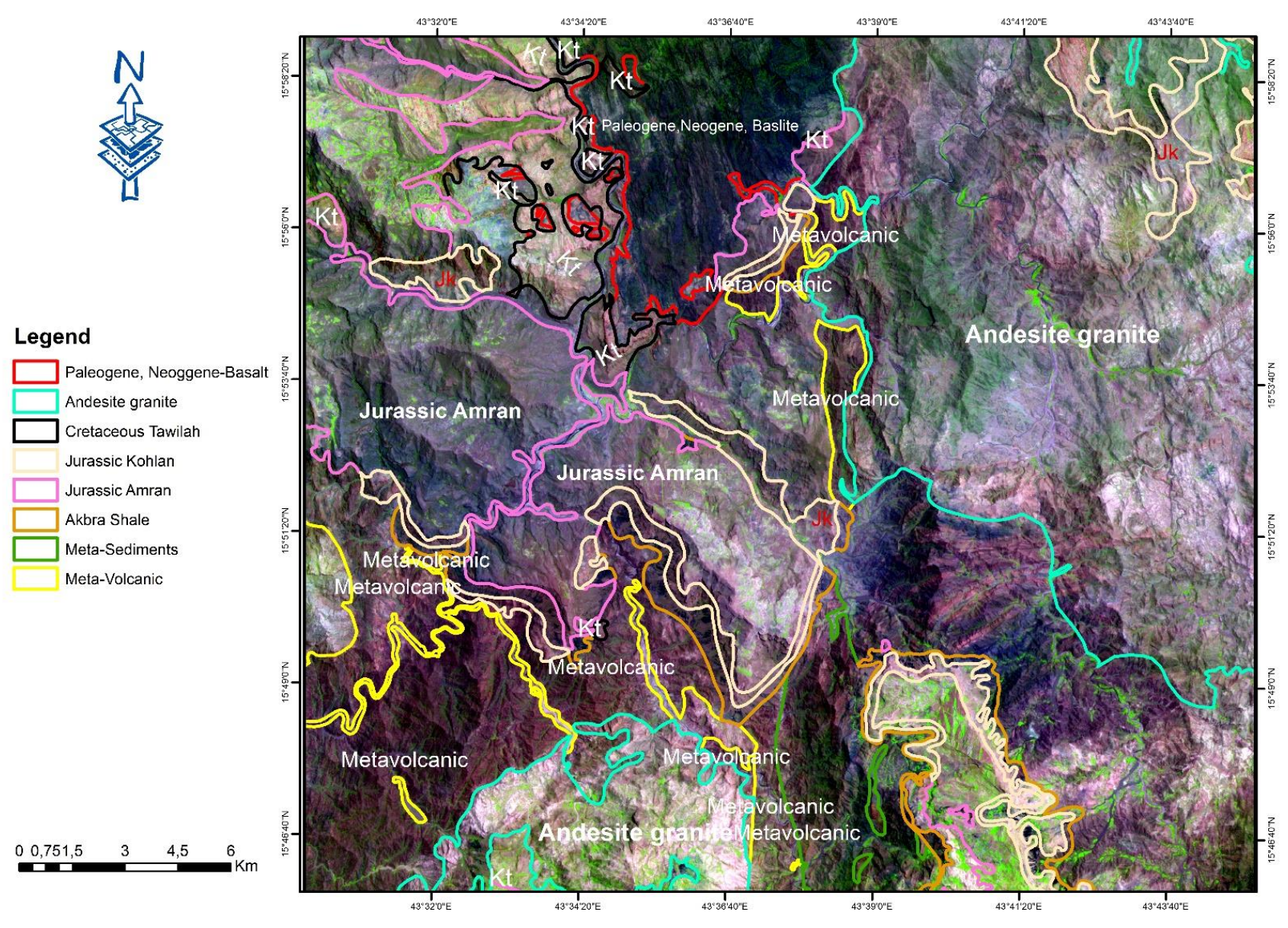

Figure 20. Final Satellite image appears

The lithological units of the study area

\subsubsection{Validation of work}

Based on the field investigation, results of the images processing, geological maps and previous studies and reports, the validity of the results has been verified, figure 20 .

\section{CONCLUSION}

The applications of OIF technique approve its efficacity to choose the suitable bands for discriminating the different rock units, also it reduces time and effort needed to select the best bands. The MNF minimum noise fraction and ICA independent component analysis enhanced the satellite images, which become facilitated for geological interpretations. In this study, we try to interpret and distingue between the unites of rocks, geological structure and fracture. Sentinel-2 has proved to be suitable for geological studies and mapping. The lithological characteristics and the ages of the geological formations on the geologic map in Figure 1, have been based on previous studies, (Heikal, 1989, YGSMB, 2006). However, it has been possible to correct a considerable number of formation boundaries on the old, small scale (1: 250,000) geological map of the YGSMB. MNF band $(1,2,3)$, ICA band $(3,4,6)$, enhancement image also helps to easy distinguished between geological formation. In this bands, the light-shadow contrast of landforms is very clear. Based on the different analyses of combinations, the OIF technique is very useful for identifying, discriminating the different rock units and another geological feature, (Qaid and Basavarajappa, 2008). The use of RGB combination involving an ICA and MNF are contributing most to enhancing geology and it has better visualization of units of rocks, structures such as the faults, shears zone and fractures, plus lithological boundaries between rocks.

\section{ACKNOWLEDGEMENTS}

We wish to thank all our reviewers who have ensured the quality of this paper is improved. We also thank the YGSMB (Yemeni geological survey and mineral resources Board) cooperation for their continued support in this research study

\section{REFERENCES}

Aapo, H., Juha, K., and Erkki, O., 2001. Independent Component Analysis, A Wiley-Interscience, publication JOHN WILEY \& SONS, INC, Final version of 7 March 2001.

Abdel Wahed, M., Zoheir, B., Hamimi. Z., and Al-Selwi, Kh. 2006. tectonic evolution of the archaean-neoproterozoic basement complex of dhi na'im-al bayda district, republic of yemen, Intern. Conf. Geol. The Arab World, Cairo Univ., Egypt. 
As-Saruri, M. A., Rasoul, S., and B.araba, R., 2010. Sedimentary basins of Yemen: their tectonic development and lithostratigraphic cover, Arab J Geosci (2010) 3:515-527.

Boardman J. W., and Kruse, F. A., 1994, Automated spectral analysis: A geologic example using AVIRIS data, north Grapevine Mountains, Nevada: in Proceedings, Tenth Thematic Conference on Geologic Remote Sensing, Environmental Research Institute of Michigan, Ann Arbor, MI, pp. 407 - 418.

Christian, M., Nina, K. B., Christian, R., Karl, K., Christoph, G., and Hermann, K., 2014. Potential applications of the sentinel-2 multispectral sensor and the enmap hyperspectral sensor in mineral exploration, EARSeL eProceedings 13, $2 / 2014$.

F.D. van der Meer, H.M.A. van der Werff, F.J.A. van Ruitenbeek, 2014. Potential of ESA's Sentinel-2 for geological applications, Remote Sensing of Environment 148 (2014), p 124-133.

Frank, P., Solveig H. W., Andreas, K., Thomas, N., and Gabriele, S., 2016. Glacier Remote Sensing Using Sentinel-2. Part II: Mapping Glacier Extents and Surface Facies, and Comparison to Landsat 8, Remote Sensing. 2016, 8, 575; doi:10.3390/rs8070575

Geosage, 2017. Spectral Discovery for Sentinel-2 Imagery, Sentinel-2 Image Sources (n.d). Copyright $\odot 2017$ GeoSage, web site. Retrieved July 2017, from

http://www.geosage.com/highview/features_sentinel2.html

Heikal, M. Th. S., Al-Khirbash, S. A., Hassan, A. M., AlKotbah, A. M., and Al-Selwi, Kh. M., 2013. Lithostratigraphy, deformation history, and tectonic evolution of the basement rocks, Republic of Yemen: an overview, Arab J Geosci.

Heikal, M. Th.S., 1989. Fracture Analysis and Tectonic Implications of Hajjah District, Yemen Arab Republic, JKAU: Earth Sci. vol. 2. pp. 69-83, (1409 A.H./ 1989 A.D.).

Ilhan, K., and Vytautas k, 1978. Application of LANDSAT Imagery to Studies of Structural Geology and Geomorphology of the Mentese Region of Southwestern Turkey, remote sensing of environment 7, 51-60(1978).

Pia, A., Mariano, F., Salvo, M., Claudio, V., and Silvia L. U., 2016. Contribution of Sentinel-2 data for applications in vegetation monitoring, ACTA IMEKO, ISSN: 2221-870X, September 2016, Volume 5, Number 2, p 44-54.

Pierre Comon., 1994. Independent component analysis, a new concept? Signal Process. 36, 287-314.

Pournamdari, M., Hashim, M., and Beiranvand Pour, A., 2014. Spectral transformation of ASTER and Landsat TM bands for lithological mapping of Soghan ophiolite complex, south Iran, Advances in Space Research 54 (2014) 694-709.

Qaid, A. M., and Basavarajappa, H.T., 2008, Application of Optimum Index Factor Technique to Landsat-7 Data for Geological Mapping of North East of Hajjah, Yemen, American-Eurasian Journal of Scientific Research 3 (1): 84-91, 2008, ISSN 1818-6785.
Qari, M.H.T., Madani, A.A., Matsah, M.I.M., and Hamimi, Z., 2008. Utilization of aster and landsat data in geologic mapping of basement rocks of arafat area, saudi arabia, The Arabian Journal for Science and Engineering, Volume 33, Number 1C, June 2008.

Sandra, J., Benjamin, B., Richard, G., Christoph, B., Hassan A. E., Khaled El Gameel, 2015. Remote sensing based improvement of the geological map of the Neoproterozoic Ras Gharib segment in the Eastern Desert (NE-Egypt) using texture features, Journal of African Earth Sciences 111 (2015) $138 \mathrm{e} 147$.

Satellite Imaging Corporation, Sentinel-2A Satellite Sensor (10m), (n.d). Copyright @ 2001-2017, web site. Retrieved June 2017, from

http://www.satimagingcorp.com/satellite-sensors/other-satellitesensors/sentinel-2a/.

Short, N. M., and Blair, R. w. (eds), 1986. Geomorphology from Space: A Global Overview of Regional Landforms. NASA., Washington, DC.

Stone, J.V., 2004. Independent Component Analysis: A Tutorial Introduction. MIT Press, Cambridge MA, 193 pp.

Tarik Bashir, B., and BIAN, F, 2005. Improved Geological Mapping Using Landsat-5 TM Data in Weixi Area, Yunnan Province, China, Geo-spatial Information Science (Quarterly), Volume 8, Issue 2, June 2005.

Veeramallu S. S., and Iyyanki V. M. K, 2016. Performance evaluation of dimensionality reduction techniques on CHRIS hyperspectral data for surface discrimination, Journal of Geomatics, Vol 10 No. 1 April 2016.

Windley Brian F., Whitehouse, M. J., and Ba-Bttat, M. A. O., 1996. Early Precambrian gneiss terranes and Pan-African island arcs in Yemen: Crustal accretion of the eastern Arabian Shield, Geology 1996;24;131-134.

Yemen Geological Survey and Mineral Resources Board, YGSMB, 2006. Report of the mineral exploration in Maghrabah.

Yemen Geological Survey and Mineral Resources Board, YGSMB, 1990. Geological map of Sana'a, $1_{\text {st }}$ edition, $1: 250.000$.

Yusuf, B.L., and Y. He, 2011. Application of hyperspectral imaging sensor to differentiate between the moisture and reflectance of healthy and infected tobacco leaves. African Journal of Agricultural Research, 6(29), 6267-6280. 